\title{
THE DELTA MODEL: A FRAMEWORK FOR THE EFFECTIVE IMPLEMENTATION OF IT TO ENABLE ORGANIZATIONAL CHANGE
}

\author{
Hanno Boekhoff \\ Renaissance Worldwide GmbH \& Co. KG \\ hboekhofferens.de
}

\begin{abstract}
This paper examines how information technology (IT) can be implemented more effectively and at the same time serve as a means to enable profound organizational change. A framework for effective IT implementation is derived and introduced and backed up by the discussion of two case studies. The findings indicate, that a strong consideration of the organizational culture is a critical factor in IT implementation, while special attention should be dedicated to the alignment of three different subcultures, that can be frequently encountered in most business organizations. It is suggested, that the consideration of the culture, highly integrated with the technological, strategical and structural aspects of IT implementation give access to a new level of accomplishment.
\end{abstract}

\section{INTRODUCTION}

Effective implementation - adaption, introduction and diffusion - of IT is, at its core, a task of managing change. As such not only technology issues are at the heart of the implementation process but structure, culture and process issues are at least equally important. Although this insight is not new, in practice, an overemphasis on the technology part can still be observed in too many cases.

Especially IT experts and managers tend to believe in "magic" and forget all they know about best practices of change management when the "magic bullet" IT comes into play, as Markus and Benjamin (1997) put it. They want the excitement of revolution without the fear and risks social upheavals bring (Kling, 1993). These findings suggest an insufficient awareness regarding the necessity of alignment between the organization and IT, and most commonly IT is pushed into the organization, based on the assumption that subsequent organizational adaptation will follow automatically. Evidence for these findings is given in many surveys (McKersie \& Walton, 1991) and is especially obvious in current efforts regarding advanced IT like groupware (SAP, etc.). 


\section{INFORMATION TECHNOLOGY AND ORGANIZATIONAL CHANGE}

The discussion about the relationship between IT and organizational change is not new. In the 40 years since the publication of Leavitt and Whisler's visionary article about management in the 1980s (Leavitt \& Whisler, 1958), numerous publications have followed.

\subsection{Causal Agency in Theoretical Models}

Markus and Robey (1988) have scanned all this material and have identified three conceptions of causal agency, beliefs about the nature of causality between IT and organizational change: the technological imperative, the organizational imperative and the emergent perspective.

Technological Imperative: This perspective assumes technology to be an external force that would have deterministic impacts on organizational properties such as structure. The social actor may have little control over appropriate action, as the use of technology is seen as the result of external constraints (Pfeffer, 1982). Strong supporters of this perspective argued that information technology would lead to structural re-centralization while a less optimistic view foresaw a re-centralization of decision making only.

Organizational Imperative: This perspective is the antithesis to the technological imperative. It focuses on the human aspects of technology, seeing technology as the outcome of strategic choice and social action. Here, IT is the dependent variable, as the assumption of this perspective is, that the human actors have almost unlimited choice over technological options and almost unlimited control over the consequences. Thus, according to this perspective, information systems are designed to satisfy organizational needs for information.

The Emergent Perspective: Empirical research on both perspectives is contradictory and suggests that either view is incomplete (Orlikowski, 1992). Information systems have been found both to enrich and routinize jobs both centralize and decentralize authority and produce no changes where changes were expected. Thus the emergent perspective holds, that there is no determinism between information technology and organizational change and that the consequences of IT emerge unpredictably. Instead of attributing change to exogenous technology or actor intent, this perspective suggests that the focus is to be put on the unique interplay among human actors, context, and technology (Gasser, 1986).

The observations outlined above suggest, that the causal agency most predominant to determine the way, the causal influence between technology and organizational change is broadly considered, is the technological imperative.

The reasons for the predominance of this perspective on the one hand can be seen in the fact, that some of the forecasts of early advocates of the technological imperative have proven true. Leavitt and Whisler's prediction, that organizations would recentralize and that many levels of middle management would disappear has become reality in most industries (Leavitt \& Whisler, 1958).

Another reason is that managers' deeply rooted assumptions about their role, the organization and organizational change very much apply to the perspective of the technological imperative. 
Managerial Assumptions about Organizational Change:

Although constantly being involved into change efforts, observations show, that managers do have an interest in preserving an existing order and very often "tend to be rooted firmly in a given understanding of reality, making acceptance of an alternative structural order and new view of the world problematic" (Orlikowski, 1991).

Beer et al. (1990) have found four main reasons, why the proclivity for what they call "programmatic change" is so predominant. (A program for change in the notion of these authors has at least one of the following characteristics: it is imposed from the top, is the centerpiece of an organizationwide initiative, is a not customized offthe-shelf standard solution, and focusses on one particular management issue, e.g. organizational structure.)

First, programs represent actions that can be put into place quickly. Managers, under pressure to present quarterly earnings are looking for actions, that promise a visible response to problems in corporate effectiveness.

Second, managers like to emulate well-known success stories. Often oversimplified lessons of "excellent" companies are buzzed by consultants and the business press, creating a pressure for action, that for most managers is hard to withstand.

Third, programs are tangible and therefore easy to measure, which allows managers to cite clear accomplishments in persuading top management of their effectiveness.

And fourth, top managers very often show a preference for delegating the implementation of change. Programmatic change projects help them to be as little involved in the change process as possible.

IT projects fit very well into the category of programmatic change: They can be put into place comparatively quickly, are easy to emulate, are tangible and easy to measure, and allow top management to keep out of the implementation process.

Another area, where IT can serve as a means for the preservation of existing structures, is hierarchical control. Being confronted with a steadily decreasing headcount in middle management, this IT capability is still being exploited extensively.

\subsection{IT as a Means of Control}

Contrary to certain expectations in literature and practice, IT is not necessarily associated with flexible or debureaucratized forms of organizing. Instead, in many cases, IT is used to exert control and as such supports the adherence to traditional forms of organizing (Orlikowski, 1991). Control through technology means, that control is embedded in the technical infrastructure of the production process. The mass production assembly line is an archetypical example for this kind of control, that today finds its equivalent in administration processes in the form of workflow management systems. In such an environment, the role of the manager changes from direct supervision to enforcing the operation of the technical system.

This same phenomenon has been observed by Zuboff. She claims that IT has mainly been used to automate, in the same manner as machines of any kind have been used to substitute human beings and the capabilities of the human body ever since the beginning of the industrial age (Zubov, 1988). No doubt, that the 
automation paradigm with its big advantages in speed and endurance has led to enormous gains in productivity. But an enormous portion of the IT-inherent capabilities have been wasted, as IT has mainly been exploited for the purpose of automation. IT is capable not only to reproduce, extend and improve human agency, but simultaneously "generate information about the underlying productive and administrative processes through which an organization accomplishes its work" (Zubov, 1988). Zuboff calls this second major and unique phenomenon the capability to "informate", that can only be exploited, when people are being empowered to use IT appropriately, which can lead to organizations being transformed into "learning institutions".

\subsection{IT-enabled Profound Change}

Research from the Massachusetts Institute of Technology Management in the 1990s Program suggests that the major reason that the benefits of IT implementation have been so slow in corning is that organizational change is not adequately managed (Morton, 1990). The sucessful implementation of IT systems has never been easy, as it is always a trigger for a confrontation of cultures (Schein, 1992). IT implementation never is only about training in how to use a tool, but it is also about changing and aligning the basic assumptions that form an organizations culture (see following section). Today, in an ever more complex business world with ever more complex business processes with an ever more complex IT-support, successful IT implementation is not possible, if change management will continue to be neglected (Benjamin \& Blunt, 1992).

Garvin (1998) delivers a very comprehensive perspective on the organization, that makes this need for change management very obvious. He distinguishes three kinds of processes, that have to be considered, to accomplish organizational transformation: work processes, behavioral processes and change processes (see Figure 1).

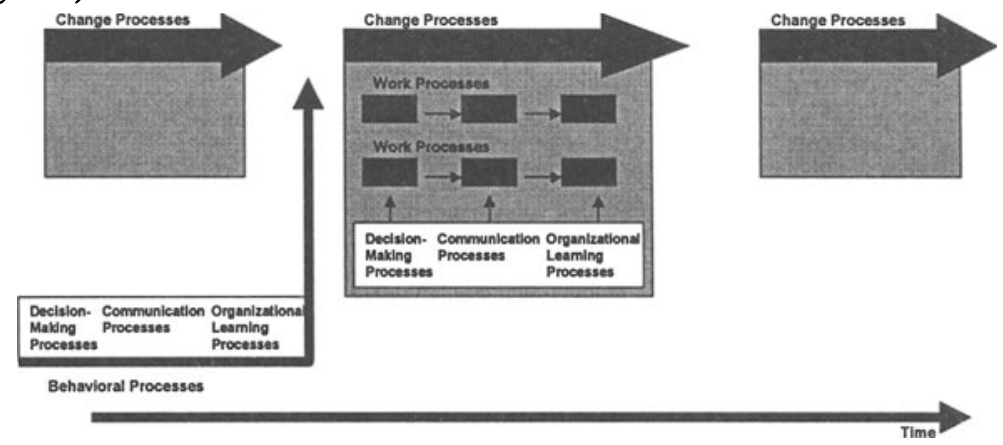

Figure 1 - A Diagram of Organizational Processes

Most change activities focus on the work processes only and most often the expected results are not being accomplished. Figure 1 shows very clearly, why any other result of e.g. a reengineering initiative would be almost serendipity. Apart from work processes there are also change processes to be considered in the organizations and both are strongly influenced by behavioral processes. The deeper 
forces in behavioral and change processes have to be tackled in the same explicit way as the work processes for real organizational transformation to occur.

The word "change", today in business and organizations means several, often contradictory things. Sometimes it refers to external changes in technology, competitors, etc., sometimes to internal changes in the organization. Change can also mean top-down programs like reorganizing, reengineering, etc.

The kind of change the remainder of this article is referring to, is what Senge et al. call "profound change" (Senge et. al, 1999). Profound change describes the combination of "inner" shifts in people's values, aspirations, and behaviors with "outer" shifts in processes, strategies, etc. The term profound change includes learning and the building of capacities for ongoing change.

\section{ORGANIZATIONAL LEARNING: A POWERFULPERSPECTIVE TO MANAGE CHANGE}

The idea of organizational learning has been around for more than thirty years, and for the first twenty or twenty-five years was one among dozens of other ideas in the field of social change, that was not receiving much attention (Argyris \& Schoen, 1996). Only recently, about ten years ago, a dramatic shift has occured that catapulted organizational learning in the midst of managerial attention and the idea, that managers' ability to learn faster than their competitors will be the only competitive advantage forcompanies in the future (de Geus, 1988), became widely accepted.

One major reason for this shift of attention by the late 1980 s is seen in the by then generally accepted recognition, that change and turbulence had become salient features in the organizational environment. As a consequence, organizations had to find ways, how to raise their capabilty for adaptation dramatically.

Regarding Garvins Organizational Diagram (see Figure 1), most organizational learning approaches do not only address organizational learning processes explicitly, but also include decision making and communication processes as well as change processes (de Geus, 1988; Senge, 1990; Watkins \& Marsick, 1993). The deeply held conviction is, that changes in strategy, structure and systems can only be achieved, when the thinking that produced those changes is changed as well (Senge et. al., 1999). In this school of thought, "organizations are products of the ways that people in them think and interact". A change of an organization for the better thus requires, that people get the opportunity to change the way they think. What is necessary then, is to provide new methods and tools, that allow a change in the way, people conduct their work.

Among the most critical skills in this context are skills for reflection and inquiry that focus around developing awareness of the attitudes and perceptions that influence behavior, thought and interaction, and that people usually are not aware of. In organizations, not only individuals have their attitudes and perceptions, but there are also shared underlying attitudes and perceptions, that are held by groups or the organization as a whole. Schein calls them basic underlying assumptions and defines them as the essence of an organizations culture (Schein, 1992). 
According to Schein, one of the reasons for the confusion about organizational culture is, that there are three different levels of cultural manifestation that are rarely differentiated:

1. artifacts (the visible organizational structures and processes)

2. espoused values (an organization's strategies, goals and philosophies) and

3. basic underlying assumptions (the unconscious, taken-for-granted attitudes, perceptions and beliefs, that guide the organizational behavior).

Most efforts in change management, that accompany IT-projects do not go further than to the level of espoused values. It is assumed that this is a major reason, why so many IT-projects fail to meet their goals and expectations. As a source of an organizational culture lies in the basic underlying assumptions, shared by its members, they need to be addressed and worked with in order to accomplish profound change.

\section{THE DELTA MODEL}

The Delta Model (Figure 2) is a framework for IT-induced organizational change that suggests the components technology, strategy/structure and culture as critical for a wholistic view on IT-introduction. Strong emphasis is put on the culture, including the consideration of the basic underlying assumptions of the actors involved, based on the notion of the organization as a pattern of communications and relations among a group of human beings as introduced in the preceding section.

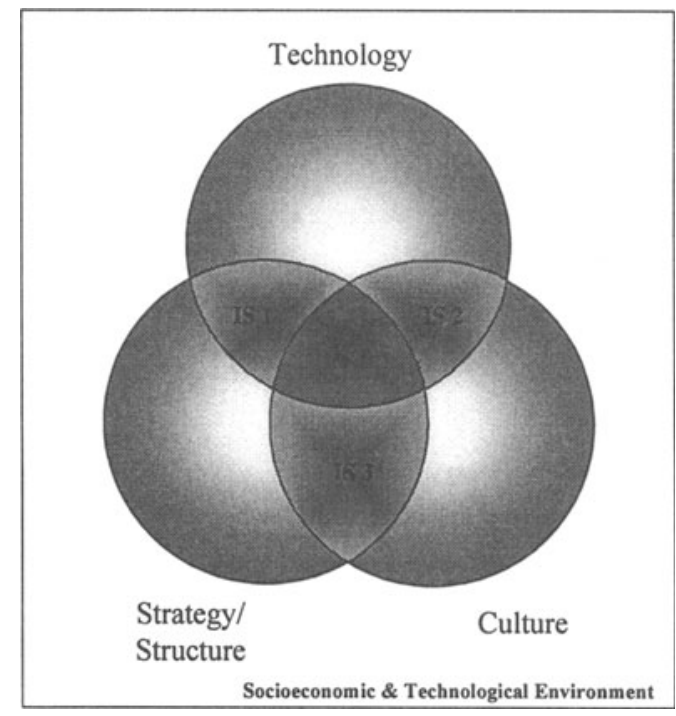

Figure 2 - The Delta Model

Additionally, the Delta Model puts a strong focus on the interfaces between the three components to stress the necessity of their alignment and to enable a wholistic view on IT-introduction. These interfaces are called "interaction spheres" (IS) and 
they not only address an alignment of the content, e.g. organizational structure, but also put special emphasis on the alignment of the basic underlying assumptions.

The emphasis on the element "culture" is not only stressed by the component culture itself, but additionally by the distinction of two layers of activity: the content layer and the assumption layer (Figure 3).

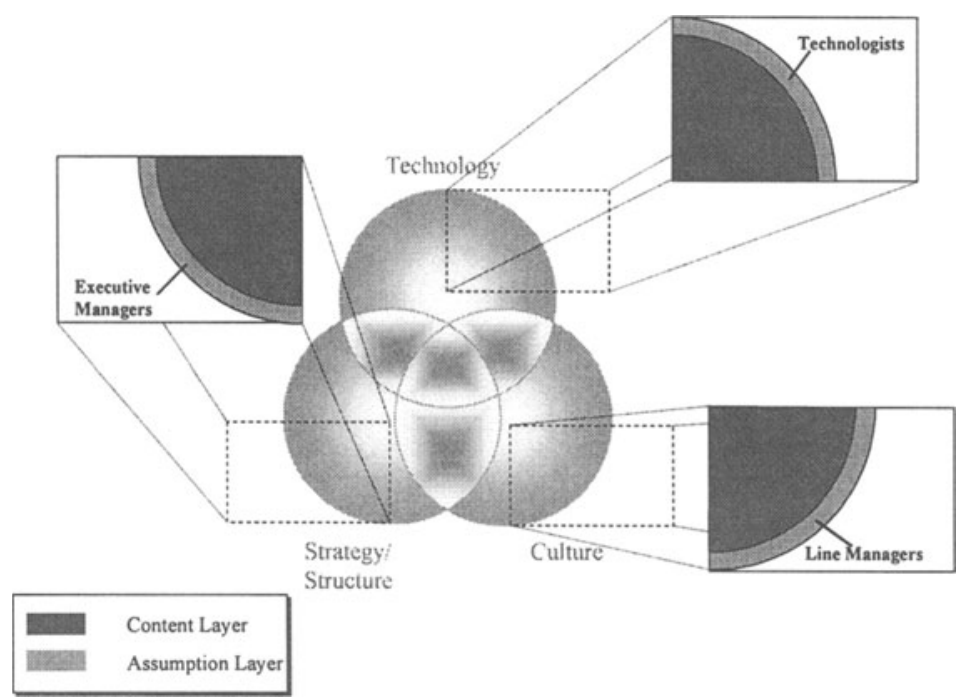

Figure 3 - Layers of the Delta Model

The background of this distinction is derived from the recognition, that one of the biggest impedements to organizational change lies in the non-alignment of three distinct cultures of management (Schein, 1996):

- Technologists who design and introduce the information technology and who usually identify themselves with their worldwide occupational community, the "engineering culture".

- Executive managers that define strategies and are responsible for the organization structure and, as with the technologists, identify themselves with their worldwide occupational community, the "executive culture".

- Line managers and line workers as the users of technology and representatives of the "operator culture", that evolves locally in organisations or organizational units.

Thus each component of the Delta Model does not only represent the factual issues of technology, strategy/structure and culture in the content layer, but also the basic assumptions of the corresponding subcultures in the assumption layer. These assumptions are forming a kind of filter or membrane around the content of each element, as depicted in figure 3 , which is considered a major source for problems, but also a major lever for success during the implementation process. These subcultures and their basic assumptions are assigned to those components they 
usually have most influence on: technologists are assigned to the component technology, executive managers to strategy/structure and line managers and workers to culture.

\subsection{Content Layers}

Technology: Jay Forrester, an eminent technologist, who not only led the team that built "Whirlwind", the first general purpose digital computer, in the early 1950s, but also invented random access core memory, an invention which put him in the Inventor's Hall of Fame in Washington D.C., recently was quoted as follows (Senge, 1996): to him "it was quite obvious, that for at least three or four generations, people would pretty much use computers to do what human beings had always done, only faster. It would take at least that long before people would use computers for doing what human beings had never done before."

This statement is a strong support for what has been elaborated in the above sections: for most organizations it is still reality, that IT is used to speed up existing processes instead of using IT as a means to enable new ways of doing business.

In order to close the gap between the potential of IT and its actual exploitation, it is crucial, that IT-strategies and business strategies are aligned from the beginning. The focus of this alignment is not put on the internal strategy only, the support of the administrative processes, derived from the business strategy, but especially on the external strategy, the position of an organization on the competitive IT-market, regarding information technology scope, systemic competencies and IT-governance (Henderson \& Venkatraman, 1993). This alignment is a dynamic process, and a critical lever lies in an organizations capability to leverage technology to differentiate its operations from competitors.

An internal IT-strategy, that is conducive to profound organizational change should include the following aspects:

Architecture: The organizations hard- and software architecture should be interconnected to the maximum. At best, it should be technically possible, that every employee has access to all existing information, to give a maximum decision support. To provide this degree of flexibility the network must support all common standards and be independent of hardware platforms.

IT-processes: The development, introduction and maintenance processes for information systems (IS) should be incremental and follow a strategy for continous improvement. Due to the extremely fast changing IT-market, the time between conception and implementation of a new IS should not exceed a time frame of nine month. Also a project should be devided into short cycles of implementation, and it should be possible to assess each cycle regarding measurable business results.

IT-roles and skills: IT-experts in modern organizations more and more will not only be assessed by their technical, but also by their social skills. The aim is to enable the users to take full advantage out of the possibilities, the technology provides, and to deal with the resistance or fears, many employees have, when faced with a new IS. The IT-expert will more and more have to become an agent of change.

Strategy/Structure: In the Delta Model strategy and organizational structure are considered as very closely interrelated and thus appear in one single component. This view is based on the fundamental assumption that economic performance 
depends on the ability to create a strategic fit between an organizations position in the competitive product market arena and the design of appropriate processes to support its execution (Rockart \& Short, 1990). In other words, what is true for the IT-strategy has its correspondence in the business strategy: external and internal strategy have to be on a high level of consistency and must be closely meshed with each other.

Much has been written recently about the structures of the new organization and a wide majority of the authors call for the elimination of the organizational chart and the hierarchy and their replacement by more flexible structures like fractals (Pasmore, 1994) or networks (Rockart \& Short, 1990). As there is no classical structure that is good for all organizations, the idea, that the hierarchy is out-dated is not supported here. There are many areas in business where, also in the future, the hierarchy will still be the most effective structure. But, regarding an organizations ability to change, to innovate, and to grow with stability, more decentralized structures are more efficient.

This argument is backed-up by research in General Systems Theory (Laszlo, 1972), where two patterns of general systems are of particular relevance in this context:

The first is the observation, that complex systems are made up of lower-level, standardized, but self-regulating, independent subsystems and the second is, that complex systems, made up of self-regulating subsystems are more stable than systems of similar size where all parts react to all stimuli.

An organizations structure also has a strong cultural aspect and according to Schein is a very important artifact of an organizations culture. The fit between a new organizational structure and the existing organizational culture has to be carefully assessed. A powerful way to create this fit is to have new processes designed bottom-up instead of top-down and to integrate participants from all affected areas into the organizational redesign.

Culture: What is true for the structure is also true for the respective information system that is to be implemented. Before introducing such a system, the fit with the culture has to be assessed. Special attention should be given to a culture's openness to change, which, admittedly, is not easy to do. There is no determined analytical structure how to analyze or to quantify the basic assumptions of an organization. Thus to decipher an organizations culture one has to begin with its visible aspects, the artifacts (Schein, 1992).

Artefacts include all the phenomena that one sees, hears and feels when encountering a new group with an unfamiliar culture. Phenomena like the architecture of the physical environment, the language or the published list of values. Of special interest is the atmosphere in meetings. Do people reflect into their own perceptions and do they inquire into their mental modells, or is their usually debate present, where one side is trying to beat down the other? Would people, when being asked about their work rather give a job description or would they speak about their goals, their customers and the quality of cooperation with their colleagues?

The next step in deciphering a culture is to ask the question "why people are doing what they are doing" (Schein, 1992). This question usually leads to value statements and gives insights into the espoused values of a culture.

The next question to be asked is, whether the identified espoused values do explain the observed artifacts or whether described artifacts have not been explained 
by or are in conflict with the articulated values. This question leads to the deeper rooted basic underlying assumptions. Shared assumptions that are conducive for profound change to occur are for example,

- the environmental context of the organization is manageable to some degree,

- human beings are by their very nature proactive problem solvers and learners,

- human nature is basically good and in any case mutable.

The bsic underlying assumptions are the access to and the lever for profound change to happen. As such they are explicitly being addressed in the assumption layer of the Delta Model.

\subsection{Assumption Layers}

In the preceding section, possible configurations in content regarding technology, strategy/structure and culture were described. Whatever configuration is chosen, its operative effectiveness is determined by the degree of alignment regarding the basic assumptions of technolgists, executive managers and line managers. The challenge is to bring these assumptions to the surface and to create time and space for this to happen. The following are a selection of typical, often contrary assumptions about IT, organization and management, human nature and learning, that have been elaborated by Schein out of 25 years of experience (Schein, 1992) and that are congruent with the findings of the cases, that are examined in this article.

\section{Assumptions of executive management:}

- Computers limit and distort thinking by focusing the user only on those kinds of data that can be packaged and transmitted.

- Hierarchy is a necessity for coordinated activity and thus intrinsic to organizations.

- Personal success and career security are measured by progress up the hierarchy.

\section{Assumptions of line management:}

- A paperless environment is not generally more efficient and desirable and the possibility to work with paper is still an important prerequisite for many tasks.

- Local units are most capable to solve their problems and do not need to be controlled.

- Technology should adapt to people and not vice versa.

\section{Assumptions of technologists:}

- More information is always better than less.

- A leaner, more automated organization will be a better one.

- People already know how to communicate and to manage and IT only needs to enhance these processes.

If these assumptions, especially those, that are in strong contrast, fail to be addressed, it is almost certain, that subtle patterns of behavior will occur, that are detrimental to the implementation process and the deployment of the respective information system. 


\subsection{Interaction Spheres}

The term "interaction sphere" was coined to address the usually neglected necessity of alignment on the assumption layer, as the assumption layer is the filter that strongly influences the alignment on the content level. Interaction spheres 1-4 are those elements of the Delta Model that provide the space for this alignment to occur.

There are many possibilities how this alignment process can be managed, but what has proven successful so far, is to begin with one or several workshops, where at least two of the subcultures are present (interaction spheres 1-3). The major assignment of those workshops is to bring the underlying fears and concerns as well as the goals on the surface and to create a vision, where the different subcultures' goals and assumptions are aligned.

What is important here is to assure, that each subcultures' fears and concerns are taken seriously and are discussed without bias. It is crucial that each subculture is able to realize, that the other subcultures have a unique capability of contribution, as they can provide know-how, the others do not have access to.

Activities in these interaction spheres not only allow the successful introduction of information systems, but also can serve as the beginning and deepening of accumulating organizational learning capability with positive effects also on other areas of the organization.

\section{CASE STUDIES}

The discussion of the two following case studies sheds light on how the elements of the Delta Model provide access to a new view on IT-implementation. The case of Dover Service Company discusses an implementation process, that was not successful, while the case of Hydro Chemicals is an example for what is possible, when the critical elements of the Delta Model are taken into account.

Dover Service Company (DSC) is the transfer agent subsidiary of Dover Mutual Funds. The transfer agent is the operational arm of a mutual fund company: it processes monetary transactions, maintains records, and services customers. DSC was established in 1990 and by June 1991 was processing all transfer agent work that was formerly done by outside contractors. By the end of 1991 DSC employed 150 employees and was noted as a new organization with a clean slate for providing improved customer service. Part of the "newness" was the promise to new hires, that advanced technologies, including imaging systems, would be utilized to improve customer servicing and employee working conditions. Imaging systems allow multiple users to work simultaneously from the same electronic document, access files using computer networks without searching through large record rooms, automatically track work and specify conditions for accessing documents with computer software. Imaging systems were first to be introduced in the customer service department (CSD). The goal for the introduction of imaging systems was more technology driven than based on clear business goals. The CEO of Dover Mutual Funds was convinced that imaging technology by itself would "transform work processes and provide dramatic benefits" and Dover wanted to be at the forefront of that technology movement. He gave the technologists all the power and 
resources they needed to implement the imaging technology as fast as possible Roth, 1993).

However, the outcomes of the project were quite disappointing. Although little gain in service quality was noted, real gains in productivity were not encountered, even a year after the system was introduced. The performance of the new system was much lower than expected, documents continued to be processed in paper form.

The introduction of document imaging at DSC mainly failed because the introduction process was dominated by the technologists which did not allow any space for cultural alignment. This domination was possible because the CEO himself was very technology focussed and believed so deeply in the contribution of the imaging system to Dover's progress that he never considered side effects. He was a typical advocate of the technological imperative and withdrew himself from the project after the vendor had been selected and the implementation had started. In this case there were no frictions between the executive and the engineering culture and no activity in interaction sphere 1 (IS 1). The technologists' view was never really questioned, which prevented a more business oriented approach. They were focussed on installing the system and producing immediate tangible results. Their technology focus did not allow them to consider somewhat more intangible business process changes. At the same time there were many frictions between the engineering and the operator culture. But because of the dominating role of the technologists, there was no alignment in IS 2. And as the CEO withdrew himself early from the project, the executive and operator culture had no space for alignment either; no efforts were dedicated to IS 3.

Hydro Chemicals is a worldwide operating Europe-based chemical company with its main business in paints and chemical additives. Hydro emerged in 1997 out of the merger of two chemical companies with complementary as well as overlapping product lines and now has 10000 employees worldwide.

To align the distinct business processes of the former two companies and to standardize the corporate IT-system, top management decided in 1997 to introduce SAP to replace most of the old heterogeneous information systems. In an earlier project, it was decided to implement about $70 \%$ of the whole SAP system and to redesign the processes according to the best practice processes of the SAP software. Within this context, the following project was carried out in one of Hydro's european subsidiaries with 600 employees, among them 200 SAP users. The timeframe for the introduction of the SAP system was 8 months and the kick-off was in summer 1998.

The project became a big success. Not only were all milestones and deadlines met during the entire project and could the system go online as scheduled, but also the system worked correctly from the beginning without any breakdowns. A letter, that was sent out during the introduction process, which suggested to all customers that they order large enough quantities of required products to get through the next couple of weeks, in case of expected system breakdowns, proved absolutely unnecessary.

Also, the atmosphere throughout the company was very positive. Everybody was happy with the new system and user acceptance was at almost $100 \%$. There were no complaints due to additional work, that had been necessary to meet the schedule and, what is even more worth mentioning, nobody from the key user group gave in notice after the project had ended. This is a very unusual phenomenon in SAP projects, as it is much more common, that a significant number of key users leave, 
when the project is over, as their SAP know-how, acquired during the project, opens many new and attractive job opportunities.

According to project leader Sabine Mrazek this success was only possible, because apart from the obligatory prerequisite of excellent IT know-how, the alignment of executive managements', technologists' and the users' goals and assumptions and thus activities in all interaction spheres were an integral part during the entire project.

The first cornerstone in this process was activity in IS 1, a workshop with executive management, the goal of which was to address all the concerns and fears that were there out of experiences with IT introductions in the past. After having brought all these issues to the surface, a new space was opened, that allowed to create the vision and the goals of the project. Also, executive management was enrolled to support a strong participation of the end users, which gave way for the bottom-up design of the new business processes and space for activity in IS 3 .

The next cornerstone was to bring in the goals and the know-how of the end users. For this purpose, several workshops were held, where end users and key users from different departments were designing the new processes with special emphasis on interface design and redundant activities.

The third cornerstone was the continuous alignment of managers, consultants, key users and end users. This alignment, which included activites in all four interaction spheres, was mainly achieved during implementation. Some top managers were involved into the implementation process which led to a continuous alignment between top managements' and users' assumptions and goals. In the same way, consultants' and key users' assumptions' and goals where aligned by continuous coaching when problems occurred.

Another result out of this continuous alignment was, that the processes designed by the end users were almost congruent with top managements' expectations, which made only few adjustments necessary.

\section{CONCLUSIONS}

This paper claims, that successful IT implementation is only for one part a function of the technology and its alignment with the business strategy and the organizational structure. The other part, that is often neglected or only superficially addressed is, that successful IT implementation is also a function of the organizational culture, into which the information system is introduced.

This insight is not new, but nevertheless only rarely applied to practice. A crucial impedement to the diffusion of this insight into practice is the attitude towards change, most managers adhere to. In order to change this status quo, further empirical evidence for the above findings is needed. Furthermore, methods and tools have to be developed, that allow to measure the success and influence of interaction sphere activities and to demonstrate, that they are not another unnecessary cost factor.

\section{REFERENCES}

1. Argyris, C. , D. Schơn. Organizational Learning II. Theory, Method, and Practice, Reading, MA: Addison-Wesley, 1996. 
2. Beer, M. , R.A. Eisenstat, B. Spector. The Critical Path to Corporate Renewal, Boston: Harvard Business School Press, 1990.

3. Benjamin, R.I. , J. Blunt "Critical IT Issues: The Next Ten Years", Sloan Management Review, Summer 1992, pp. 7-19.

4. Garvin, D.A. "The Processes of Organization and Management", Sloan Management Review, Summer 1998, pp. 33-50.

5. Gasser, L. "The Integration of Computing and Routine Work", ACM Transactions on Office Information Systems, Vol. 4, No. 3, 1986, pp. 205-225.

6. de Geus, A. , "Planning as Learning", Harvard Business Review, March-April, 1988, pp. 129-134.

7. Henderson, J.C. N. Venkatraman. "Strategic Alignment: Leveraging Information Technolgy for Transforming Organizations", IBM Systems Journal, Vol. 32, No. 1, 1993, pp. 4-16.

8. Kling, R. "Cooperation, Coordination and Control in Computer Supported Cooperative Work", Communications of the ACM, Vol. 34, No. 12, 1993, pp. 83-88.

9. McKersie, R.B., R.E. Walton. Organizational Change. In: M.S. Scott-Morton (ed), The Corporation of the 1990s. Information Technology and Organizational Transformation, New York: Oxford University Press, 1991, pp. 244-277.

10. Leavitt, H.J., L. Whisler. "Management in the 1980s", Harvard Business Review, Vol. 36, 1958, pp. 41-48.

11. Laszlo, E. The Relevance of General Systems Theory, New York: George Braziller, 1972.

12. Markus, M.L., D. Robey. "Information Technology and Organizational Change: Causal Structure in Theory and Research", Management Science, Vol. 34, No. 5, 1988, pp. 583-598.

13. Markus, M.L., R.J. Benjamin. The magic bullettheory in IT-enabled transformation, Sloan Management Review, 1997, pp. 55-68.

14. Orlikowski, W. "The Duality of Technology: Rethinking the Concept of Technology in Organizations", Organization Science, Vol. 3, No. 3, 1992, pp. 398-427.

15. Orlikowski, W. "Integrated Information Environment or Matrix of Control? The Contradictory Implications of Information Technology", Accounting, Management and Information Technology, Vol. 1, No. 1, 1991, pp. 9-42.

16. Pasmore, W.A. Creating Strategic Change: Designing the Flexible, High-performing Organization, New York: Wiley\&Sons, 1994.

17. Pfeffer, J. Organizations and Organization Theory, Marshfield, MA: Pitman, 1982.

18. Rockart, J.F. ,J.E. Short. The Networked Organization and the Management of Interdependence. In: M.S. Scott Morton (ed.), The Corporation of the 1990s, New York: Oxford University Press, pp. 189-219.

19. Roth, G. In Search of the Paperless Office: The Structuring Waves of Technological Change. Massachusetts Institute of Technology, Ph.D. dissertation, Cambridge, MA 1993.

20. Senge, P., A. Kleiner; C. Roberts; R. Ross; G. Roth; B. Smith, The Dance of Change. The Challenges to Sustaining Momentum in Learning Organizations. New York: Doubleday, 1999.

21. Scott Morton, M.S. (ed.), The Corporation of the 1990s, New York: Oxford University Press, pp. 13-23.

22. Schein, E.H. Organizational Culture and Leadership, $2^{\text {nd }}$ edition, San Francisco: Jossey-Bass, 1992.

23. Senge, $P$. The Fifth Discipline. the Art and Practice of the Learning Organization, New York: Doubleday, 1990.

24. Schein, E.H. "Three Cultures of Management: The Key to Organizational Learning", Sloan Management Review, Fall 1996, pp. 9-20.

25. . Senge, P. "Through the Eye of the Needle". In: Gibson, R. (ed.), Rethinking the Future:Rethinking Business, Principles, Competition, Control, Leadership, Markets and the World, London: Brealey Publishing, 1996, pp. 122-145.

26. Watkins, K.E., V.J. Marsick. Sculpturing the Learning Organization: Lessons in the Art and Science of Systemic Change, San Francisco: Jossey-Bass, 1993.

27. Zuboff, $S$. In the age of the smart machine, the future of work and power. Basic Books, New York, 1988. 